\title{
Médiévales
}

Langues, Textes, Histoire

81 | automne 2021

Voix laïques $\left(\mathrm{XI}^{\mathrm{e}}-\mathrm{XIII}\right.$ siècle $)$

\section{Catherine Verna et Sandrine Victor (dir.), Los carniceros y sus oficios (España-Francia, ss. xiii-xvi)}

Valence, Publicacions de la Universitat de València, 2020, 304 p.

\section{Benoît Descamps}

\section{OpenEdition}

\section{Journals}

Édition électronique

URL : https://journals.openedition.org/medievales/12030

DOI : $10.4000 /$ medievales. 12030

ISSN : 1777-5892

\section{Éditeur}

Presses universitaires de Vincennes

Édition imprimée

Date de publication : 12 janvier 2022

Pagination : 210-212

ISBN : 978-2-37924-202-1

ISSN : 0751-2708

\section{Référence électronique}

Benoît Descamps, «Catherine Verna et Sandrine Victor (dir.), Los carniceros y sus oficios (España-

Francia, ss. xiii-xvi) », Médiévales [En ligne], 81 | automne 2021, mis en ligne le 28 janvier 2022, consulté le 22 avril 2022. URL : http://journals.openedition.org/medievales/12030 ; DOI : https://doi.org/ 10.4000/medievales.12030

Ce document a été généré automatiquement le 22 avril 2022

Tous droits réservés 


\title{
Catherine Verna et Sandrine Victor (dir.), Los carniceros y sus oficios (España-Francia, ss. xiii-xvi)
}

\author{
Valence, Publicacions de la Universitat de València, 2020, 304 p.
}

\section{Benoît Descamps}

\section{RÉFÉRENCE}

Catherine Verna et Sandrine Victor (dir.), Los carniceros y sus oficios (España-Francia, ss. xiii-xvi), Valence, Publicacions de la Universitat de València, 2020, 304 p.

1 Pour introduire ce recueil d'articles consacré aux bouchers et à leurs affaires en Espagne et en France (méridionale) entre le XIII et le $\mathrm{Xv}^{\mathrm{e}}$ siècle, Catherine Verna et Sandrine Victor rappellent le caractère singulier de ce corps de métier en apparence longtemps marginalisé, tant dans la société médiévale que par l'historiographie. Tout en éclairant les démarches adoptées par la douzaine de contributeurs (sortir du schéma simpliste ville versus campagne, multiplier les angles d'observation, concilier études quantitatives et micro-histoire...), elles annoncent a contrario le rôle d'interface essentiel joué par ces artisans-marchands-entrepreneurs entre mondes urbain et rural. Les premières pistes de réflexion sont confirmées par la suite de l'ouvrage structuré en quatre parties thématiques dont la première est consacrée à l'approvisionnement des villes et aux compétences des bouchers.

Dans «l'apport de l'élevage de Minorque à l'approvisionnement des boucheries majorquaines et catalanes à la fin du Moyen Âge » (p. 27-72), Antoni Riera i Melis décrit les conséquences sur tout un bassin économique de l'histoire mouvementé des Baléares et en particulier de Minorque, reconquise sur les musulmans, puis intégrée à l'Aragon, bouleversée par la peste noire, une famine en 1373, la guerre civile au $\mathrm{xv}^{\mathrm{e}}$ siècle... modifiant les marchés et parfois les formes de consommation carnée. Source de revenus fiscaux, capital suscitant des vols, le cheptel intéressa les autorités et anima la 
production des fermes minorquines. Dans «boucheries et commerce de viande dans le royaume d'Aragon au Xve siècle » (p. 73-100), étudiant taxes et péages, mais également les parcours biographiques de bouchers aragonais à travers les comptes municipaux de villes petites ou moyennes et les sources notariales, Germán Navarro Espinach et Concepción Villanueva Morte dévoilent l'implication de ces hommes dans les lucratifs marchés locaux de la viande et des autres produits issus de l'abattage (cuir, suif) leur permettant de s'insinuer dans les élites politiques rurales pour mieux contrôler le circuit d'approvisionnement et en particulier les enchères de la gestion municipale de ce marché. Juan Vicente García Marsilla propose une approche microéconomique des "grandes boucheries de Valencia à la fin du Moyen Âge" (p. 101-130) à travers, en particulier, l'étude de riches tableaux de prix. Il met ainsi en lumière le fonctionnement géographique et fiscal du monopole, ainsi que les investissements et les bénéfices d'une activité vitale et lucrative, décrivant les actions des "señors utils", ces grands propriétaires d'étaux qui construisirent des dynasties durables et influentes dans la ville et le royaume.

Débutant une deuxième partie sur les liens entre la boucherie et l'industrie, l'article de Juliette Sibon porte sur « les bouchers de Marseille au xIv siècle. Affaires, réseaux et pouvoirs à la ville et dans la campagne environnante » (p. 133-151). Elle y démontre que la boucherie était une entreprise libre, c'est-à-dire sans cadre corporatif, où bouchers chrétiens, juifs et convertis, travaillaient côte à côte, et plus souvent en association, ce que la ségrégation sur les comportements religieux alimentaires ne pouvait laisser imaginer, l'activité demeurant toutefois sous la surveillance des autorités comtales, municipales ou cléricales. Par l'usage du crédit pour leurs affaires qui s'élargirent régulièrement et par la circulation dans un bassin d'approvisionnement associant l'arrière-pays au marché de la viande, les bouchers marseillais constituèrent un noyau d'hommes d'affaires essentiels aux emboîtements économiques urbains et ruraux. À partir d'une quarantaine de contrats, Ricardo Córdoba de la Llave étudie « les bouchers et le commerce des peaux dans le royaume de Cordoue à la fin du Moyen Âge (1460-1520) " et signale l'ampleur géographique de l'approvisionnement en matière première utile aux artisans cordouans du cuir et fournit une typologie des peaux avec leur prix. Là encore, il souligne la domination des bouchers sur ce marché, en dépit (ou à cause) des contraintes d'un dépeçage soigneux ménageant la peau et les chairs à consommer. Par une mise en miroir des sources urbaines et rurales, entre plaine du Roussillon et Pyrénées, Catherine Verna (p.179-196) confirme l'interpénétration des hommes et des activités entre villes et campagnes dans l'exemple des bouchers du Vallespir en Catalogne ( $\mathrm{xv}^{\mathrm{e}}$ siècle). À travers le marché des peaux, les tractations complexes autour de la fiscalité ou - moins attendu - le développement de la métallurgie autour d'Arles-sur-Tech et Perpignan, se révèle la position en interface de ces marchands-artisans devenus brasseurs d'affaires, dans un mécanisme plus subtil que la simple domination des campagnes par les villes.

Une troisième partie se concentre sur les réseaux constitués par les liens familiaux et les affaires. Joel Colomer (p. 199-218) se penche sur les bouchers de Besalu (Nord est de la Catalogne) et plus précisément sur l'exemple de deux familles dont les affaires au début du XIV ${ }^{e}$ siècle ont suscité la création de registres notariaux particuliers. Il décrit comment, par le crédit, les Forn et les Mas s'insinuent dans l'économie des campagnes environnantes parvenant par des contrats spécifiques à assurer leur approvisionnement en bétail voire à transformer les paysans en employés, chargés 
d'engraisser du bétail introduit par ces acteurs devenus primordiaux dans le développement rural de la couronne d'Aragon. Johan Paris propose une étude microhistorique (p. 219-239) portant sur deux générations d'une famille de Millau dans la seconde moitié du XIv ${ }^{e}$ siècle et révélant une ascension sociale : le fils grand marchand, devenu consul intègre l'oligarchie millavoise par élargissement des affaires entre le Rouergue et Lodève, jusqu'en Avignon, mais en s'appuyant sur le cercle d'affaires constitué initialement par le père, simple boucher. Ramón A. Banegas López a consacré son attention à la famille Citjar qui associa la viande, l'argent et le pouvoir dans la Barcelone du $\mathrm{Xv}^{\mathrm{e}}$ siècle (p. 241-251). Il y décrit en particulier la fortune croissante de Joan Citjar traduite par l'augmentation du nombre de moutons vendus et d'étals détenus et par la construction d'un foisonnant réseau social familial, professionnel et politique, ce qui lui permit malgré les guerres - ou grâce aux bouleversements qu'elles occasionnèrent - de protéger son approvisionnement en amont, en particulier depuis Puigcerdà (Cerdagne) et son commerce florissant en aval dans la capitale catalane.

Un dernier chapitre se concentre sur les bouchers castillans comme illustration de la force des petites villes et des bourgs. Pour aborder leur commerce entre villes et villages d'une région sujette aux difficultés propres de la Reconquista impliquant réorganisation territoriale et politique, Mariana Zapatero (p. 259-278) examine les ordonnances, régulant voire créant les pâturages, limitant l'exportation de bétail hors d'un espace dont elles cherchent à protéger l'approvisionnement. Elle les confronte ensuite à une série de litiges ayant donné lieu à procès, lesquels confirment la conversion et la spécialisation des espaces ruraux dans des économies de plus en plus marquées par l'élevage et la consommation de viande. David Carvajal de la Vega clôt l'ouvrage par une synthèse sur les bouchers et leurs affaires dans le monde rural castillan à la fin $d u \mathrm{XV}^{\mathrm{e}}$ et au début du $\mathrm{XVI}^{\mathrm{e}}$ siècle (p. 279-301), confirmant ce rôle d'agents du développement des campagnes tenus par ces commerçants compétents et expert dans l'organisation des circuits d'approvisionnement, la mise en place de compagnies, par leur connaissance enfin de la circulation monétaire et au final des hommes comme de leurs territoires.

6 L'ensemble de toutes ces contributions offre le panorama cohérent d'une histoire rurale renouvelée par l'étude des relations étroites et complexes entre villes, bourgs et villages, mettant fin à des distinctions traditionnelles qui nuisent le plus souvent à la compréhension globale du fonctionnement économique médiéval: les campagnes n'étaient pas que des espaces dominés par la ville, mais plutôt étroitement associées à leur développement; les hommes d'un métier, à partir d'un certain seuil, ne se cantonnaient pas dans une seule activité, mais élargissaient en fonction de leur réseau initial la palette de leur talent, saisissant toutes les possibilités offertes; les circonstances politiques difficiles ou les contraintes de l'espace n'empêchaient pas la circulation des hommes, des bêtes et des capitaux, et certainement pas les initiatives dynamiques, qui révélaient un réel esprit d'entreprise. Ce travail collectif cohérent, complémentaire et rarement répétitif concrétise surtout l'obligation faite à l'historien d'exploiter des ressources croisées, de multiplier les approches, de la micro-histoire à l'étude des cycles longs. 


\section{AUTEURS}

BENOÎT DESCAMPS

LaMOP UMR 8589 